\title{
Effects of perceived role clarity on innovative work behavior: a multiple mediation model
}

\author{
Subhash C. Kundu, Sandeep Kumar and Kusum Lata \\ Haryana School of Business, \\ Guru Jambheshwar University of Science and Technology, Hisar, India
}

\begin{abstract}
Purpose - The purpose of this study is to assess the effect of perceived role clarity on innovative work behavior (IWB) through the mediation of intrinsic motivation and job involvement.

Design/methodology/approach - The data were gathered from 613 employees belonging to 196 organizations operating in India. Data were analyzed using statistical tools such as exploratory and confirmatory factor analysis, multiple regressions and bootstrapping via PROCESS.
\end{abstract}

Findings - Initially, the results of correlation and multiple regression analyses indicated that the perceived role clarity has positive relation with intrinsic motivation, job involvement and IWB. Further, bootstrap analysis revealed that intrinsic motivation and job involvement individually and serially mediate the effect of perceived role clarity on IWB.

Research limitations/implications - The study highlights the importance of the perceived role clarity in developing positive work attitudes and innovative behavior among employees. Self-reported survey and cross-sectional design are the limitations of the current study.

Practical implications - The study suggests that organizations should strive constantly to enhance perceptions of role clarity among employees so that they remain motivated and involved in their jobs and exhibit innovative behavior at work.

Originality/value - To the best of the authors' knowledge, this is the only study to test the impact of perceived role clarity on IWB with the serial mediation of intrinsic motivation and job involvement.

Keywords Perceived role clarity, Intrinsic motivation, Job involvement,

Serial mediation innovative work behavior, India

Paper type Research paper

\section{Introduction}

In this highly competitive business environment, creativity and innovative work have become critically important for organizational viability (Damanpour \& Gopalakrishnan, 2001; Forrester, 2000). Organization's ability to innovate largely depends on the extent of innovative work behavior (IWB) of individual employees (De Jong \& Den Hartog, 2007).

(c) Subhash C. Kundu, Sandeep Kumar and Kusum Lata. Published in RAUSP Management Journal. Published by Emerald Publishing Limited. This article is published under the Creative Commons Attribution (CC BY 4.0) licence. Anyone may reproduce, distribute, translate and create derivative works of this article (for both commercial and non-commercial purposes), subject to full attribution to the original publication and authors. The full terms of this licence may be seen at http:// creativecommons.org/licences/by/4.0/legalcode

Authors contributions: Subhash C. Kundu led the reviewing and editing of this paper. Sandeep Kumar led the writing of the original draft, and Kusum Lata was in charge of the methodology of the work. All authors contributed equally to all other aspects of the work.
Innovative work behavior

Received 16 April 2019

Revised 17 July 2019

2 August 2019

27 August 2019

Accepted 8 September 2019 
RAUSP

55,4

According to De Jong and Den Hartog (2008), IWB refers to "an individual's behavior that aims to achieve the initiation and intentional introduction (within a work role, group or organization) of new and useful ideas, processes, products or procedures." As employees are not bound to exhibit IWB because it does not come under their formal job requirements, the organization has to depend on the willingness of employees to exhibit this extra role behavior (Huhtala \& Parzefall, 2007). Given the importance of IWB for the organization, interest of management scholars is escalating in understanding the predictors of IWB (Mueller, 2019; Yasir \& Majid, 2019).

Studies have explored the relationship of various factors with IWB, such as innovative climate, open and supportive environment, psychological empowerment, inclusive leadership, perceived organizational support, job autonomy, transformational leadership and job complexity (Bibi \& Afsar, 2018; Hammond, Neff, Farr, Scwall, \& Zhao, 2011; Hon, 2012a); however, perceived role clarity has not been studied much as an antecedent of IWB. Although perceived role clarity has been found an important antecedent for various employee outcomes such as job performance, efficiency, organizational commitment, organizational citizenship behavior and job satisfaction (Hassan, 2013; Mukherjee \& Malhotra, 2005; Samie, Riahi, \& Tabibi, 2015), its relationship with IWB is still obscure because of the lack of adequate research. Some studies have tried to understand the relationship of role clarity and IWB (Ohly, Sonnentag, \& Pluntke, 2006), but the scholarly research on their relationship is inadequate. Furthermore, results of the existing studies are inconclusive and contradictory. Some studies have advocated that lower specificity is good for IWB (Thompson, 1965). On the other hand, some studies have highlighted that lack of role clarity leads to anxiety and depression, thus, reducing IWB (Caplan \& Jones, 1975). Reason of these inconsistencies may be that previous studies have ignored the mediating role of psychological mechanisms while studying perceived role clarity and IWB.

The present study intends to fill this gap by studying the mediating role of intrinsic motivation and job involvement in the relationship of perceived role clarity and IWB. Although the mediating role of these two important variables have not been empirically tested yet, the existing literature provides some indications regarding their mediating role between perceived role clarity and IWB. Huhtala and Parzefall (2007) argued that employees exhibit innovative behavior when they have ability and willingness to innovate. Shalley and Gilson (2004) emphasized that employees need strong internal forces such as intrinsic motivation to overcome the challenges of IWB.

Razak, Zakaria, and Mat (2017) stressed that employee attitudes are crucial because they affect their job behaviors. Almost four decades ago, Moch (1980) emphasized the lack of studies to examine the effect of job characteristics on intrinsic motivation and job involvement. Still there is dearth of studies which have explored the relationship of role clarity with intrinsic motivation and job involvement. To address these gaps, we intend to examine the role of intrinsic motivation and job involvement as means through which perceived role clarity influences IWB.

In a nutshell, the current study intends to explore the following research question: What is the mechanism through which perceived role clarity is related with IWB? To answer this research question, the main objective of the study is to assess the effects of perceived role clarity on IWB. Further, to achieve this main objective, following are the sub-objectives:

- to investigate the direct effect of perceived role clarity on intrinsic motivation, job involvement and IWB;

- to explore the indirect influence of perceived role clarity on IWB through intrinsic motivation and job involvement; and 
- to investigate the sequential mediation of intrinsic motivation and job involvement between the relationship of perceived role clarity and IWB.

Innovative work behavior

The following sections of the paper will discuss literature review and hypotheses development, research methodology, results, discussion, implications of the study and limitations and future research directions.

\section{Literature review and hypotheses development}

2.1 Perceived role clarity and intrinsic motivation

Deci and Ryan (1985) defined intrinsic motivation as performance of an activity for the inherent enjoyment and satisfaction. Role clarity increases intrinsic motivation among employees because they know that their efforts will lead to certain outcomes (Tubre \& Collins, 2000). Mukherjee and Malhotra (2005) found that role clarity makes positive impact on various employee outcomes such as job satisfaction and organizational commitment. On the other side, lack of role clarity generates stress among employees which is very detrimental for creativity (Jackson \& Schuler, 1985). So, to clarify this relationship, the hypothesis is:

H1a. The perceived role clarity is positively related to intrinsic motivation.

\subsection{Perceived role clarity and job involvement}

Job involvement can also be an important consequence of role clarity, although there is little empirical evidence to prove their relationship. Role clarity reduces the unnecessary confusion from the employees' mind regarding their roles and consequently, they do their job tasks with high involvement (Hassan, 2013). Gormley (2003) indicated that role conflict and role uncertainty along with other variables make negative impact on job involvement. Study of Ju et al. (2013) found that role clarity has positive impact on job involvement through the moderation of employee goal orientation . Further, Walia and Narang (2015) found that role ambiguity is negatively correlated with job involvement. So, we propose:

H1b. The perceived role clarity is positively related to job involvement.

\subsection{Intrinsic motivation and job involvement}

Studies have shown that intrinsically motivated employees exhibit high work engagement and have less intention to leave the organization (Kundu, Mehra, \& Mor, 2017; Putra, Seonghee, \& Liu, 2015). Study of Hsu (2012) found that intrinsic motivation and self-efficacy work as a mediator between perceived person-job fit and job involvement of employees. Cho and Perry (2012) observed that intrinsic motivators are three times more effective than extrinsic motivators in terms of enhancing employee engagement. Razak et al. (2017) expressed job involvement as an attitudinal consequence of intrinsic motivation. Therefore, the hypothesis is:

H1c. Intrinsic motivation is positively related to job involvement.

2.4 Perceived role clarity and innovative work behavior

IWB refers to the combination of generation, promotion, and implementation of new ideas (Janssen, 2003). When employees have clarity about their roles, they do not need repeated 
RAUSP

55,4 instructions about daily work tasks and they can use this spared time and cognitive resources to generate and implement new ideas (Ohly et al., 2006). When employees lack role clarity, they spend more time in finding out what they are required to do instead of doing job tasks effectively (Onyemah, 2008). Chu, Lee, and Hsu (2006) found that when employees have unclear roles, they exhibit less extra-role behaviors. Therefore, the hypothesis is:

H2. The perceived role clarity is positively related to innovative work behavior.

\subsection{Intrinsic motivation and innovative work behavior}

Intrinsic motivation is more effective than extrinsic rewards in developing IWB among employees (Sanders, Moorkamp, Tprka, Groeneveld, \& Goeneveld, 2010). In a longitudinal research design, Devloo, Anseel, Beuckelaer, and Salanova (2015) found that the effect of basic need satisfaction on IWB is mediated by intrinsic motivation. In the context of Pakistan, the study of Bibi and Afsar (2018) found that leader-member exchange (LMX) has strong effect on IWB when the level of intrinsic motivation and psychological empowerment is high among employees. Bysted and Hansen (2013) have also explained that employees become more innovative when they are intrinsically motivated. Challenging jobs encourage employees to indulge in IWB by enhancing their intrinsic motivation (Sanders et al., 2010). So, the hypothesis is:

$H 3 a$. Intrinsic motivation is positively related to innovative work behavior.

\subsection{Job involvement and innovative work behavior}

Taştan (2013) found that job involvement moderates the relationship between participative organizational climate and innovative behavior. Employees with high job involvement may take the risk of conflict and reduced satisfaction with their co-workers, which can arise because of their indulgence in innovative activities (Janssen, 2003). Brown (2007) also stressed the importance of deep work involvement of employees for IWB. In a study of Chinese IT enterprises, Huang, Yuan, and Li (2019) found that job involvement mediates the relationship between person-job fit and IWB. Further, Garg and Dhar (2017) observed that the influence of LMX on employee service innovative behavior is fully mediated by employee's work engagement. So, the next hypothesis is:

H3b. Job involvement is positively related to innovative work behavior.

\subsection{Mediating role of intrinsic motivation and job involvement in the relationship of perceived role clarity and innovative work behavior}

Many studies have proved that organizational and environmental factors influence employee creativity and innovation through the mediation of intrinsic motivation (Hon, 2012a; Shalley \& Gilson, 2004). In a study, Hon (2012a) found that the effects of contextual factors on employee creativity are mediated by intrinsic motivation. Saeed, Afsar, Shahjehan, and Shah (2019) discovered that transformational leadership makes strong impact on IWB when intrinsic motivation and psychological empowerment are high among employees. Further, Sherman (1989) postulated that role clarity induces motivation among employees and motivated employees solve problems in innovative ways. Caillier (2016) found that goal clarity has a positive effect on organization commitment and extra role behaviors with the mediation of public service motivation. Role clarity also makes positive 
impact on job involvement which further leads to more IWB (Taştan, 2013). Therefore, we propose the following hypothesis:

Innovative work behavior

H4. Intrinsic motivation and job involvement mediate the positive relationship between perceived role clarity and innovative work behavior.

Despite playing the role of separate mediators between role clarity and IWB, both the mediators, i.e. intrinsic motivation and job involvement, can also have a relationship with each other. Mgedezi, Toga, and Mjoli (2014) have found a positive association between intrinsic motivation and job involvement. Lee, Amarmend, and Lee (2011) discovered that intrinsic motivation has a positive influence on job involvement and satisfaction directly as well as indirectly through the moderation of distributive and procedural justice. Therefore, the hypothesis is:

H5. The positive relationship between perceived role clarity and innovative work behavior is serially mediated by intrinsic motivation and job involvement.

\section{Research methodology}

\subsection{Sample}

As the study was concerned with the Indian corporate sector, the organizations operating in India were the prime focus of the study. From the organizations listed on Federation of Indian Chambers of Commerce and Industry, a list of 500 companies operating in India was carefully drawn. HR heads of these organizations were contacted and requested to participate in the survey through electronic mail and LinkedIn. Finally, a total of 196 organizations agreed to participate in the survey. In all 980 questionnaires were administered to these 196 organizations by ensuring that at least five questionnaires per organization must be served. After repeated reminders, 711 filled up questionnaires were received. Out of 711 questionnaires, 98 incomplete questionnaires were dropped. Finally, a total of 613 questionnaires were retained for further analysis resulting in an effective response rate of 62.55 per cent. Distribution and characteristics of the sample can be seen in Table I.

\subsection{Measures}

Detailed description about measurement scales used in the survey is summarized in Table II. All measures were assessed on a five-point Likert scale ranging from 1 "strongly disagree" to 5 "strongly agree". Cronbach alphas were also calculated to gauge the reliability of the measured items.

3.2.1 Perceived role clarity (independent variable) Five items scale of perceived role clarity was taken from the study of Mukherjee and Malhotra (2005). It was measured with five items $(\alpha=0.834)$.

3.2.2 Intrinsic motivation and job involvement (mediating variables) Intrinsic motivation was taken from the scale of Zhang and Bartol (2010). It contained three items $(\alpha=0.809)$. Another mediating variable, i.e. job involvement was measured with the scale of Gazzoli, Hancer, and Park (2012). It was measured with five items $(\alpha=$ $0.859)$.

3.2.3 Innovative work behavior (dependent variable) The dependent variable was measured with four item scale adapted from the study of Ma Prieto and Pérez-Santana (2014). The reliability of the scale is quite high $(\alpha=0.810)$. 


\begin{tabular}{|c|c|c|c|c|c|}
\hline \multirow{5}{*}{$\begin{array}{l}\text { RAUSP } \\
55,4\end{array}$} & \\
\hline & Variables & Categories & No. & $(\%)$ & Average \\
\hline & Gender & Female & 75 & 12.2 & \\
\hline & & Male & 538 & 87.8 & \\
\hline & & Total & 613 & 100.0 & \\
\hline \multirow{4}{*}{462} & Sector & Private & 411 & 67.0 & \\
\hline & & Public (government) & 202 & 33.0 & \\
\hline & & Total & 613 & 100.0 & \\
\hline & Ownership & Indian & 531 & 86.6 & \\
\hline & & MNCs/collaborates & 82 & 13.4 & \\
\hline & & Total & 613 & 100.0 & \\
\hline & Nature & Service company & 396 & 64.6 & \\
\hline & & Manufacturing company & 217 & 35.4 & \\
\hline & & Total & 613 & 100.0 & \\
\hline & Education & Postgraduate & 227 & 37.0 & \\
\hline & & Undergraduate & 386 & 63.0 & \\
\hline & & Total & 613 & 100.0 & \\
\hline & Age & Under 25 years & 105 & 17.1 & \\
\hline & & $26-30$ years & 250 & 40.8 & \\
\hline & & $31-40$ years & 159 & 25.9 & 31.22 \\
\hline & & 41-50 years & 53 & 8.6 & \\
\hline \multirow{2}{*}{$\begin{array}{l}\text { Table I. } \\
\text { Distribution and }\end{array}$} & & 51-60 years & 45 & 7.3 & \\
\hline & & Above 60 years & 1 & 0.2 & \\
\hline
\end{tabular}

Notes: Number of organizations included: 196. MNCs/collaborates here represent multinational corporations

\subsection{Control variables}

Gender, education, and age were controlled for their influence on the study variables. Coding for these variables were as follows: gender $(1=$ male, $0=$ female), education $(1=$ undergraduates, $0=$ postgraduates), and age ( $1=$ up to 25 years, $2=25-30$ years, $3=$ $31-40$ years, $4=41-50$ years, $5=51-60$ years and $6=$ above 60 years).

\subsection{Statistical tools applied}

Analysis of the data was performed by using various statistical techniques including means, standard deviations, correlations, factor analysis, multiple regressions and bootstrapping.

\subsection{Common method bias}

As there was one single source of data collection, i.e. self-reported questionnaire, therefore, the problem of common method bias might exist. To gauge the magnitude of common method variance, single factor test via CFA was applied to all the variables. The derived single factor revealed a very poor fit $\left(\chi^{2} / \mathrm{df}=13.989\right.$; goodness-of-fit index $[\mathrm{GFI}]=0.717$ Tucker-Lewis index $[\mathrm{TLI}]=0.636$; comparative fit index $[\mathrm{CFI}]=0.685$; root mean square error of approximation [RMSEA] $=0.146$ ). Thus, there was no possibility of common method bias (Podsakoff, MacKenzie, Lee, \& Podsakoff, 2003).

\section{Results}

\subsection{Factor analysis}

Varimax rotated factor analysis was applied on the 17 items relating to four scales. Detailed results of exploratory factor analysis (EFA) can be seen through Table II. 


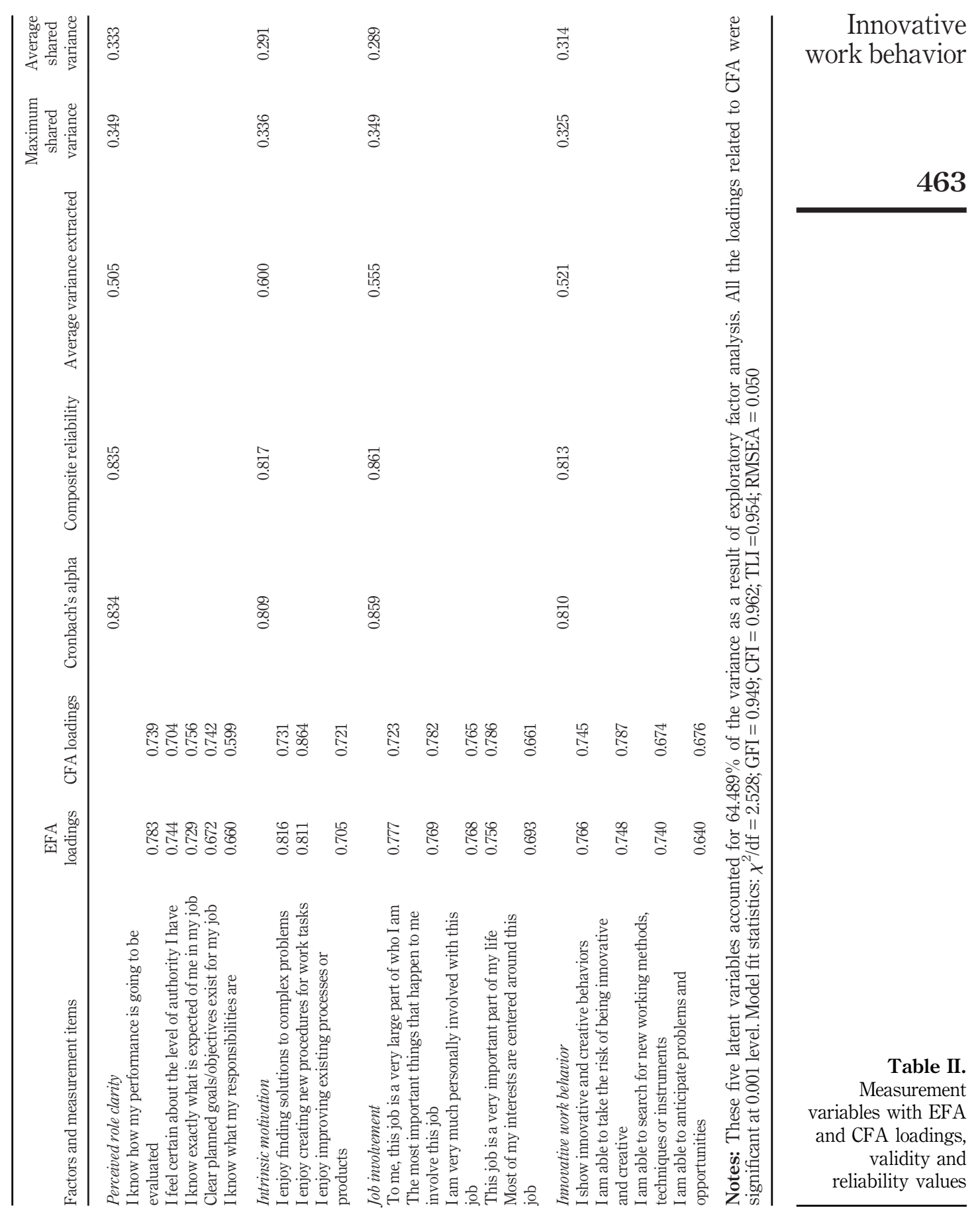


RAUSP

55,4

464

After applying EFA, to validate the established constructs, confirmatory factor analysis (CFA) was conducted. CFA results were scrutinized with the help of indices such as $\chi^{2} / \mathrm{df}$ (Chi-square goodness of fit-to-degrees of freedom ratio), CFI, TLI, GFI and RMSEA. Standard criteria for well-developed model were as follows: $\chi^{2} / \mathrm{df}<3$, acceptable up to 5; $\mathrm{GFI} \geq 0.9 ; \mathrm{TLI} \geq 0.9$; CFI $\geq 0.9$; RMSEA $\leq 0.08$ (Hair, Black, Babin, \& Anderson, 2010). The results of CFA for the four latent variables were $\chi^{2} / \mathrm{df}=2.528$; GFI $=0.949$; $\mathrm{CFI}=0.962$; $\mathrm{TLI}=0.954$ and RMSEA $=0.050$. These model fit indices revealed a better fit. Thus, the model confirmed the dimensionality of the four constructs. In terms of convergent validity, we computed the composite reliability (CR) and average variance extracted (AVE). CR for each construct were ranged from 0.813 to 0.861 , greater than the standard of 0.70 (Zhao \& Cavusgil, 2006). AVE for each construct were ranged from 0.505 to 0.600 , higher than 0.50 (Hair et al., 2010). Therefore, the constructs confirmed the convergent validity (Zhao \& Cavusgil, 2006). Both maximum shared variance (MSV) and average shared variance (ASV) were calculated and found to be less than the average variance extracted. Therefore, the discriminant validity was confirmed (Hair et al., 2010).

\subsection{Descriptive statistics}

Table III represents means, standard deviations, and intercorrelations of the study variables. The extent of the means showed that perceived role clarity, intrinsic motivation, job involvement, and IWB were practiced at reasonable level. Further, correlations among predictor and outcome variables were found significant to indicate the hypothesized linkages.

\subsection{Regression analysis}

Table IV summarizes the multiple regression analysis results. The procedure suggested by Baron and Kenny (1986) was used to check the mediation. The study found that perceived role clarity, intrinsic motivation, job involvement, and IWB were significantly related with each other, these could be included in the path model for the multiple meditation analyses (Table IV). The proposed hypotheses have been tested with the help of multiple regression analyses and the mediation hypotheses were tested with the help of bootstrap procedure (Hayes, 2012). All the regression models were found significant, according to F statistics (Table IV). Model 1 and Model 2 established the direct effect of perceived role clarity on intrinsic motivation $\left(\beta=0.491^{* * *}, \mathrm{p} \leq 0.001\right)$ and job involvement $\left(\beta=0.500^{* * *}\right.$, $\mathrm{p} \leq$ 0.001). Therefore, these results supported the H1a and H1b. Model 3 captured the direct effect of intrinsic motivation on job involvement $(\beta=0.387 * * *, \mathrm{p} \leq 0.001)$, therefore,

Table III.

Means, standard deviations and correlations

\begin{tabular}{|c|c|c|c|c|c|c|c|c|c|c|}
\hline Variables & $\begin{array}{l}\text { No. of } \\
\text { items }\end{array}$ & Mean & SD & 1 & 2 & 3 & 4 & 5 & 6 & 7 \\
\hline Gender & - & 0.88 & 0.328 & - & & & & & & \\
\hline Education & - & 0.63 & 0.483 & $0.105^{* *}$ & - & & & & & \\
\hline Age & - & 2.49 & 1.108 & $0.178 * * *$ & -0.047 & - & & & & \\
\hline Perceived role clarity & 5 & 3.984 & 0.641 & 0.069 & -0.010 & 0.065 & - & & & \\
\hline Intrinsic motivation & 3 & 3.960 & 0.634 & 0.071 & -0.021 & 0.006 & $0.492 * * *$ & - & & \\
\hline Job involvement & 5 & 3.905 & 0.675 & $0.082 *$ & 0.065 & $0.102 *$ & $0.505^{* * * *}$ & $0.388 * * *$ & - & \\
\hline Innovative work behavior & 4 & 3.991 & 0.601 & 0.005 & -0.005 & 0.069 & $0.472^{* * *}$ & $0.473 * * *$ & $0.470^{* * * *}$ & $=$ \\
\hline
\end{tabular}


supporting H1c. Model 4 captured the direct effect of perceived role clarity on IWB ( $\beta=$ $\left.0.471^{* * *}, p \leq 0.001\right)$, therefore, supporting H2. Model 5 and model 6 captured the direct effect of mediators i.e. intrinsic motivation and job involvement on IWB $\left(\beta=0.476^{* * *}\right.$, $p \leq 0.001 ; \beta=0.472^{* * *}, p \leq 0.001$, respectively). These results supported the H3a and H3b.

Further, we used the bootstrap procedure suggested by Hayes (2012) for estimation of direct and indirect path linking perceived role clarity and IWB. The results of bootstrapping procedure are exemplified in Tables V and VI. The PROCESS model (6) was applied for estimating the effects of perceived role clarity on IWB through serial mediation of intrinsic motivation and job involvement. Model 10 represents the total effects of perceived role clarity on IWB $\left(\beta=0.442^{* * *}, \mathrm{p} \leq 0.001\right)$. Thus, this result confirmed the validation of $H 2$. Model 9 represents the mediated indirect effect of perceived role clarity on IWB $(\beta=$ $\left.0.193^{* * *}, \mathrm{p} \leq 0.001\right)$. Significant reduction in the value of perceived role clarity path coefficient indicates the relevance of indirect paths in the relationship between perceived role clarity and IWB. Thus, $H 4$ was confirmed. All the $\mathrm{F}$ statistics were found significant. Figure 1 shows the predicted paths along with their estimates for representation of serial multiple mediation analysis.

\begin{tabular}{lcccccc}
\hline & Intrinsic motivation & \multicolumn{2}{c}{ Job involvement } & \multicolumn{2}{c}{ Innovative work behaviour } \\
Independent variables & Model 1 & Model 2 & Model 3 & Model 4 & Model 5 & Model 6 \\
\hline Gender & 0.046 & 0.028 & 0.033 & -0.036 & -0.043 & -0.034 \\
Education & -0.022 & 0.071 & 0.062 & 0.006 & 0.013 & -0.031 \\
Age & -0.036 & 0.068 & $0.088^{*}$ & 0.044 & 0.074 & 0.025 \\
Perceived role clarity & $0.491^{* * *}$ & $0.500^{* * *}$ & - & $0.471^{* * *}$ & - & - \\
Intrinsic motivation & - & - & $0.387^{* * *}$ & - & $0.476^{* * *}$ & - \\
Job involvement & - & - & - & - & - & $0.472^{* * * *}$ \\
$R^{2}$ & 0.245 & 0.266 & 0.165 & 0.225 & 0.230 & 0.224 \\
Adjusted $R^{2}$ & 0.240 & 0.261 & 0.160 & 0.220 & 0.225 & 0.219 \\
F statistic & $49.373^{* * * *}$ & $55.123^{* * *}$ & $33.516^{* * * *}$ & $44.203^{* * * *}$ & $45.446^{* * * *}$ & $43.785^{* * * *}$
\end{tabular}

Notes: $* * * p \leq 0.001 ; * p \leq 0.05$
Innovative work behavior

465

Table IV. Results of multiple regression analyses testing the proposed association among study variables

\begin{tabular}{|c|c|c|c|c|}
\hline \multirow[b]{2}{*}{ Independent variables } & \multirow{2}{*}{$\begin{array}{c}\text { Intrinsic motivation } \\
\text { Model } 7\end{array}$} & \multirow{2}{*}{$\begin{array}{l}\text { Job involvement } \\
\text { Model } 8\end{array}$} & \multicolumn{2}{|c|}{ Innovative work behaviour } \\
\hline & & & Model 9 & Model 10 \\
\hline Gender & $0.089(0.069)$ & $0.039(0.072)$ & $-0.101(0.061)$ & $-0.065(0.067)$ \\
\hline Education & $-0.029(0.046)$ & $0.104 *(0.048)$ & $-0.008(0.041)$ & $0.007(0.044)$ \\
\hline Age & $-0.020(0.020)$ & $0.045 *(0.021)$ & $0.019(0.018)$ & $0.024(0.019)$ \\
\hline Perceived role clarity & $0.485 * * * *(0.035)$ & $0.429 * * *(0.041)$ & $0.193 * * *(0.038)$ & $0.442 * * *(0.033)$ \\
\hline Intrinsic motivation & - & $0.198 * * *(0.041)$ & $0.259 * * *(0.036)$ & - \\
\hline Job involvement & - & - & $0.231 * * * *(0.034)$ & - \\
\hline$R$ & 0.495 & 0.540 & 0.593 & 0.474 \\
\hline$R^{2}$ & 0.245 & 0.292 & 0.352 & 0.225 \\
\hline F statistic & $49.373^{* * * *}$ & $50.178^{* * *}$ & $54.859 * * *$ & $44.208 * * *$ \\
\hline
\end{tabular}

Notes: The numbers in parentheses 0 represent standard error; Model 10 highlights the total effect of perceived role clarity on IWB and Model 9 highlights the mediated direct effect of perceived role clarity on IWB; $* * * p \leq 0.001$; and $* p \leq 0.05$
Table V.

Multiple mediation results derived from OLS regression using PROCESS 
RAUSP

55,4

466

Based on a bootstrap results with 5,000 re-samples and bias-corrected and accelerated (BCa) 95 per cent confidence interval, as recommended (Preacher \& Hayes, 2008), did not contain zero at all in all the indirect paths. All the three indirect paths establishing the link between perceived role clarity and IWB have confirmed the mediating effect of intrinsic motivation and job involvement (Table VI). Thus, $H 4$ was reconfirmed. Considering the sequential indirect path (i.e. perceived role clarity $\rightarrow$ intrinsic motivation $\rightarrow$ job involvement $\rightarrow$ IWB), the confidence interval did not contain zero, confirming the sequential mediation of intrinsic motivation and job involvement in the relationship between perceived role clarity and IWB. Therefore, $H 5$ was also confirmed by the study results.

\section{Discussion}

In this highly competitive environment, innovativeness has become very crucial for the organizational success (Hon, 2012b). Organizations are much interested to find ways of

\begin{tabular}{llcccc}
\hline S. No. & Indirect effects & Effect & Standard error & Boot LLCI & Boot ULCI \\
\hline Ind1 & Total Effect & 0.248 & 0.028 & 0.194 & 0.307 \\
& $\begin{array}{l}\text { Perceived role clarity } \rightarrow \text { intrinsic } \\
\text { motivation } \rightarrow \text { IWB }\end{array}$ & 0.126 & 0.024 & 0.081 & 0.177 \\
Ind2 & $\begin{array}{l}\text { Perceived role clarity } \rightarrow \text { intrinsic } \\
\text { motivation } \rightarrow \text { job involvement } \rightarrow\end{array}$ & 0.022 & 0.007 & 0.009 & 0.039 \\
Ind3 & $\begin{array}{l}\text { IWB } \\
\text { Perceived role clarity } \rightarrow \text { job } \\
\text { involvement } \rightarrow \text { IWB }\end{array}$ & 0.099 & 0.020 & 0.063 & 0.144
\end{tabular}

Table VI.

Completely standardized indirect effects of perceived role clarity on IWB through mediators

Notes: Ind1-Ind3 represent the indirect effects derived from bootstrap procedure. Boot LLCI stands for bootstrapped accelerated lower limit confidence interval, and boot ULCI, for bootstrapped accelerated upper limit confidence interval

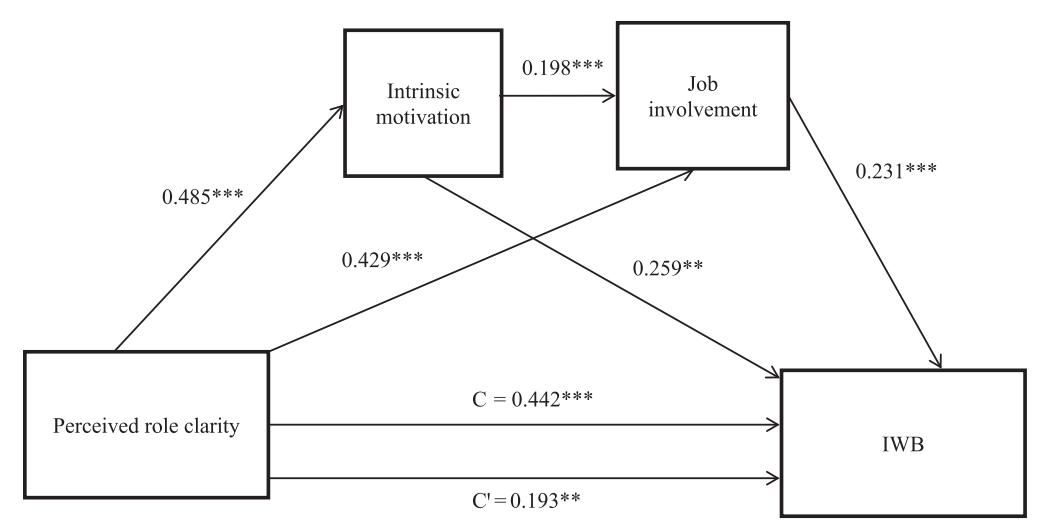

Figure 1.

Estimated serial multiple mediation model
Notes: (a) $\mathrm{C}$ represents total effects of perceived role clarity on IWB; $\mathrm{C}^{\prime}$ represents indirect effects of perceived role clarity on IW; (b) the numbers in the above figure represent the path coefficients derived from the models using PROCESS; (c) ${ }^{* * *} p \leq 0.001 ; * * p \leq 0.01$ 
motivating employees to work with innovativeness because employees cannot be bound to exhibit IWB by job descriptions (Agarwal, 2014). As described in the introduction section, some past studies have tried to understand the relationship of perceived role clarity with IWB, but the results of these studies are inconclusive (Hammond et al., 2011). To gain some better understanding about their relationship, the current research has explored the serialmultiple mediation of intrinsic motivation and job involvement as well as their individual mediation between the relationship of perceived role clarity and IWB.

The first important finding of the study is that role clarity has a direct positive impact on

IWB. When employees have good understanding of their work roles, they tend to behave innovatively at work. Findings of the current research agree with previous research findings (Lynn \& Kalay, 2015). Jada, Mukhopadhyay, and Titiyal (2019) observed that empowering leadership make stronger impact on IWB in presence of high role clarity. Samie et al. (2015) found that employee work more efficiently when they have high perceived role clarity. Dalal (2018) rightly stated that when employees are not clear about their roles, they waste their energy in confusion instead of executing their tasks.

Further examination of multiple mediations shows that both intrinsic motivation and job involvement partially mediate between perceived role clarity and IWB. These findings of the study confirm the notion that the relationship of perceived role clarity and IWB is not as simple as it seems. These results of the study can be explained in reference to the selfdetermination theory (Deci \& Ryan, 1985). According to this theory, contextual factors either enhance or diminish intrinsic motivation of the employees before leading to further work outcomes (Hon, 2012b). Tierney and Farmer (2002) explained that individuals need strong internal forces to sustain their creative efforts and face the challenges of creative work. These two forces may be intrinsic motivation and job involvement. Highly involved employees participate in their jobs eagerly, which enable them to behave creatively. Fossey and Harvey (2010) rightly stated that highly motivated and involved workforce is prerequisite to achieve any organizational goal.

Results of serial mediation found that intrinsic motivation as first mediator makes positive impact on job involvement which finally influences the innovative behavior of employees in a positive way. When employees are intrinsically motivated, they experience deeper involvement with their job. Lee et al. (2011) also proved the positive association between intrinsic motivation and job involvement. Exploring this relationship further, the current study explored their interactive effects between perceived role clarity and IWB. Results indicate that intrinsic motivation, induced by perceived role clarity, make positive impact on employee innovativeness both directly and indirectly through the channel of job involvement. This kind of serial mediation has not been checked in the past. So this is the novel contribution to management and behavioral literature.

\section{Implications of the study}

The present study has several theoretical as well as practical implications. On theoretical ground, the study is a significant contributor to the field of perceived role clarity, intrinsic motivation, job involvement and IWB, as no study had, to the knowledge of the authors, yet examined their relationship together. So, little was known about the psychological processes, which can work as a mediating mechanism between perceived role clarity and IWB. This study has tried to uncover those mechanisms. Another new contribution of the study is the examination of the serial mediation of intrinsic motivation and job involvement between perceived role clarity and IWB.

Considering the practical implications, the study gives many insights for the organizations to make their employees more innovative. The first implication is regarding 
RAUSP

55,4

the clarity of roles. Organizations always find it challenging to motivate and involve their employees in their job. The results of the study clearly indicate that there are ample benefits of perceived role clarity in the form of employee outcomes. Organizations should create the environment which leads to higher perceived role clarity among employees. While employees feel confused about their work role, they cannot be motivated and involved in their jobs, which are crucial for an IWB. Management can improve role clarity among employees by clarifying work objectives and role expectations consistently (Hassan, 2013). Jada et al. (2019) rightly expressed that managers should not only focus on establishing clear role descriptions but also communicate to employees what is expected from them. In a study of call center representatives in UK, Mukherjee and Malhotra (2005) found three significant predictors of role clarity, namely, feedback, participation in decision-making, and team support. Organizations can improve role clarity among employees by focusing on these predictors. Managers must train employees to enhance their understanding about work roles and ensure that employees have the necessary skills and abilities to fulfill those roles effectively. In this highly dynamic business environment, roles of employees keep changing rapidly. Employees must be given detailed information instantly even with the slightest change in their work role before they feel confused and perplexed. Nansubuga and Munene (2013) advised that managers must articulate the required competencies among employees whenever they experience any role ambiguity. Organizations should take care at the time of recruitment and selection of new employees. At the time of the recruitment, recruiters must be clear about the expected role of the new recruits and should convey them properly.

The study also found empirical support for positive effect of intrinsic motivation and job involvement on innovative behavior. These findings support the notion that employees need strong internal drives to work innovatively (Hammond et al., 2011). Employees get excited to generate and implement new ideas only when they get internally motivated to their job and get deeply involved in their jobs. Even though perceived role clarity has been found the predictor of intrinsic motivation and job involvement, managers must consider other predictors to enhance motivation and involvement of employees. Implementation of high performance work systems (HPWS) has been found very effective to enhance the motivation among Indian employees (Kundu \& Gahlawat, 2016). Managers must understand and consider these mechanisms to enhance motivation, involvement and IWB among employees.

\section{Limitations and future research directions}

As every research study has some limitations, this study is also not free from them. Because the data have been collected from the single source i.e. self-administered questionnaire, it can lead to common method bias. For this reason, we have embraced some statistical (single factor test) and procedural measures (mixing the questions of different scale) to avoid the common method bias (Podsakoff et al., 2003). Therefore, it was not the main issue in our study. Next, the current study was cross-sectional in nature. It is hard to establish a causal relationship among study variables. Future researchers can overcome this limitation by adopting the longitudinal research design by collecting the data at different points of time for more generalization of the results. Another limitation of the study was that only individual-level factors have been taken as a predictor and mediating variables. Future study can be conducted with an appropriate mixture of individual and organizational level factors with IWB to get a deeper understanding (Hammond et al., 2011). 


\section{References}

Innovative

Agarwal, U. A. (2014). Examining the impact of social exchange relationships on innovative work behaviour: Role of work engagement. Team Performance Management, 20, 102-120.

Baron, R. M., \& Kenny, D. A. (1986). The moderator-mediator variable distinction in social psychological research: Conceptual, strategic, and statistical considerations. Journal of Personality and Social Psychology, 51, 1173-1182.

Bibi, A., \& Afsar, B. (2018). Leader-member exchange and innovative work behavior: The role of intrinsic motivation, psychological empowerment, and creative process engagement. Perspectives of Innovations, Economics and Business, 18, 25-43.

Brown, S. P. (2007). Job involvement. Encyclopedia of industrial and organizational psychology, pp. 397-399. Thousand Oaks: Sage Publications.

Bysted, R., \& Hansen, J. (2013). Comparing public and private sector employees' innovative behavior. Public Management Review, 17, 1-20.

Caillier, J. G. (2016). Does public service motivation mediate the relationship between goal clarity and both organizational commitment and extra-role behaviours? Public Management Review, 18, 300-318.

Caplan, R. D., \& Jones, K. W. (1975). Effects of work load, role ambiguity, and type: A personality on anxiety, depression, and heart rate. The Journal of Applied Psychology, 60, 713-719.

Cho, Y. J., \& Perry, J. L. (2012). Intrinsic motivation and employee attitudes: role of trustworthiness, goal directedness and extrinsic reward expectancy. Review of Public Personnel Administration, 32, 382-406.

Chu, C. I., Lee, M. S., \& Hsu, H. M. (2006). The impact of social support and job stress on public health nurses' organizational citizenship behaviors in rural Taiwan. Public Health Nursing, 23, 496-505.

Dalal, B. (2018). The importance of role clarity and role ambiguity for leaders. Retrieved from http:// www.fortuneindia.com/opinion/the-importance-of-role-clarity-and-role-ambiguity-for-leaders/ 101609

Damanpour, R., \& Gopalakrishnan, S. (2001). The dynamics of the adoption of product and process innovations in organizations. Journal of Management Studies, 38, 45-65.

De Jong, J. P. J., \& Den Hartog, D. N. (2007). How leaders influence employees' innovative behavior? European Journal of Innovation Management, 10, 41-64.

De Jong, J. P. J., \& Den Hartog, D. N. (2008). Innovative work behaviour: Measurement and validation. EIM Business and Policy Research, 1, 1-27.

Deci, E. L., \& Ryan, R. M. (1985). Intrinsic motivation and Self-Determination in human behavior, New York, NY: Springer Science \& Business Media.

Devloo, T., Anseel, F., Beuckelaer, A. D., \& Salanova, M. (2015). Keep the fire burning: Reciprocal gains of basic need satisfaction, intrinsic motivation and innovative work behavior. European Journal of Work and Organizational Psychology, 24, 491-504.

Forrester, R. H. (2000). Capturing learning and applying knowledge: An investigation of the use of innovation teams in Japanese and American automotive firms. Journal of Business Research, 47, $35-45$.

Fossey, E. M., \& Harvey, C. A. (2010). Finding and sustaining employment: A qualitative Metasynthesis of mental health consumer views. Canadian Journal of Occupational Therapy, 77, 303-314.

Garg, S., \& Dhar, R. (2017). Employee service innovative behavior: The roles of leader-member exchange (LMX), work engagement, and job autonomy. International Journal of Manpower, 38, 242-258.

Gazzoli, G., Hancer, M., \& Park, Y. (2012). Employee empowerment and customer orientation: Effects on workers' attitudes in restaurant organizations. International Journal of Hospitality \& Tourism Administration, 13, 1-25. 
RAUSP

55,4

Gormley, D. K. (2003). Factors affecting job satisfaction in nurse faculty: A meta-analysis. Journal of Nursing Education, 42, 174-178.

Hair, J. F., Jr, Black, W. C., Babin, B., \& Anderson, R. E. (2010). Multivariate data analysis, NJ: Prentice Hall. (7th ed.)

Hammond, M. M., Neff, N. L., Farr, J. L., Schwall, A. R., \& Zhao, X. (2011). Predictors of individual-level innovation at work: A meta-analysis. Psychology of Aesthetics, Creativity, and the Arts, 5, 90-105.

Hassan, S. (2013). The importance of role clarification in workgroups: Effects on perceived role clarity, work satisfaction, and turnover rates. Public Administration Review, 73, 716-725.

Hayes, A. F. (2012). PROCESS: A versatile computational tool for observed variable mediation, moderation, and conditional process modeling. Retrieved from www.afhayes.com/public/ process2012.pdf

Hon, A. H. Y. (2012a). Shaping environments conductive to creativity: The role of intrinsic motivation. Cornell Hospitality Quarterly, 53, 53-64.

Hon, A. H. Y. (2012b). When competency-based pay relates to creative performance: The moderating role of employee psychological need. International Journal of Hospitality Management, 31, 130-138.

Hsu, Y. R. (2012). Mediating roles of intrinsic motivation and self-efficacy in the relationships between perceived person-job fit and work outcomes. African Journal of Business Management, 6, 2616-2625.

Huang, W., Yuan, C., \& Li, M. (2019). Person-job fit and innovation behavior: Roles of job involvement and career commitment. Frontiers in Psychology, 10, 1-10.

Huhtala, H., \& Parzefall, M. R. (2007). A review of employee well-being and innovativeness: An opportunity for mutual benefit. Creativity and Innovation Management, 16, 299-306.

Jackson, S. E., \& Schuler, R. S. (1985). A meta-analysis and conceptual critique of research on role ambiguity and role conflict in work settings. Organizational Behavior and Human Decision Processes, 36, 16-78.

Jada, U. R., Mukhopadhyay, S., \& Titiyal, R. (2019). Empowering leadership and innovative work behavior: A moderated mediation examination. Journal of Knowledge Management, 23, 915-930.

Janssen, O. (2003). Innovative behaviour and job involvement at the price of conflict and less satisfactory relations with co-workers. Journal of Occupational and Organizational Psychology, $76,347-364$.

Ju, D., Jiao, J., Zhang, W., \& Huang, M. (2013). Effects of role clarity and person-job fit on job involvement: goal orientations as moderators. Academy of Management Proceedings, 2013, doi: https://doi.org/10.5465/ambpp.2013.13646abstract.

Kundu, S. C., \& Gahlawat, N. (2016). High performance work systems and employees' intention to leave: Exploring the mediating role of employee outcomes. Management Research Review, 39, 1587-1615.

Kundu, S. C., Mehra, L., \& Mor, A. (2017). Effect of diversity management on employees' intention to quit: Mediating role of employee motivation. Journal of Strategic Human Resource Management, $6,17-27$.

Lee, S. K., Amarmend, D., \& Lee, D. J. (2011). The effects of intrinsic motivation on job satisfaction and job involvement: Focus on the moderate effects of procedural justice, distributive justice. Journal of Digital Convergence, 9, 157-168.

Lynn, G., \& Kalay, F. (2015). The effect of vision and role clarity on team performance. Pressacademia, 4, 473-499.

Ma Prieto, I., \& Pérez-Santana, M. P. (2014). Managing innovative work behavior: The role of human resource practices. Personnel Review, 43, 184-208.

Mgedezi, S., Toga, R., \& Mjoli, T. (2014). Intrinsic motivation and job involvement on employee retention: Case study-a selection of Eastern Cape government departments. Mediterranean Journal of Social Sciences, 5, 2119-2126. 
Moch, M. K. (1980). Job involvement, internal motivation, and employees' integration into networks of work relationships. Organizational Behavior and Human Performance, 25, 15-31.

Mueller, B. (2019). The building blocks of creativity and new ideas. RAUSP Management Journal, 54, 242-246.

Mukherjee, A., \& Malhotra, N. (2005). Antecedents and consequences of role clarity in explaining employee-perceived service quality in call centres. American Marketing Association, 17, $15-17$.

Nansubuga, F., \& Munene, J. C. (2013). Reflecting on competences to increase role clarity during service delivery in a third world setting. Journal of Workplace Learning, 25, 231-246.

Ohly, S., Sonnentag, S., \& Pluntke, F. (2006). Routinization, work characteristics and their relationships with creative and proactive behaviors. Journal of Organizational Behavior, 27, 257-279.

Onyemah, V. (2008). Role ambiguity, role conflict, and performance: Empirical evidence of an invertedU relationship. Journal of Personal Selling \& Sales Management, 28, 299-314.

Podsakoff, P. M., MacKenzie, S. B., Lee, J. Y., \& Podsakoff, N. P. (2003). Common method biases in behavioural research: A critical review of the literature and recommended remedies. Journal of Applied Psychology, 88, 879-903.

Preacher, K. J., \& Hayes, A. F. (2008). Asymptotic and resampling strategies for assessing and comparing indirect effects in multiple mediator models. Behavior Research Methods, 40, 879-891.

Putra, E. D., Seonghee, C., \& Liu, J. (2015). Extrinsic and intrinsic motivation on work engagement in the hospitality industry: Test of motivation crowding theory. Tourism and Hospitality Research, 17, 228-241.

Razak, H. A., Zakaria, N., \& Mat, N. (2017). The relationship between psychological empowerment and job involvement. Journal of Applied Structural Equation Modeling, 1, 44-61.

Saeed, B. B., Afsar, B., Shahjehan, A., \& Shah, S. I. (2019). Does transformational leadership foster innovative work behavior? The roles of psychological empowerment, intrinsic motivation, and creative process engagement. Perspectives of Innovations, Economics and Business, 32, 254-281.

Samie, F., Riahi, L., \& Tabibi, S. J. (2015). The relationship between role clarity and efficiency of employees in management \& resource development department of ministry of health and medical education of IR Iran, 2014. Biosciences, Biotechnology Research Asia, 12, 2803-2812.

Sanders, K., Moorkamp, M., Tprka, N., Groeneveld, S., \& Goeneveld, C. (2010). How to support innovative behaviour? The role of LMX and satisfaction with HR practices. Technology and Investment, 1, 59-68.

Shalley, C. E., \& Gilson, L. L. (2004). What leaders need to know: A review of social and contextual factors that can foster or hinder creativity. The Leadership Quarterly, 15, 33-53.

Sherman, J. D. (1989). Technical supervision and turnover among engineers and technicians. Group \& Organization Studies, 14, 411-421.

Taştan, S. B. (2013). The influences of participative organizational climate and self-leadership on innovative behavior and the roles of job involvement and proactive personality: A survey in the context of SMEs in Izmir. Procedia - Social and Behavioral Sciences, 75, 407-419.

Thompson, V. A. (1965). Bureaucracy and innovation. Administrative Science Quarterly, 10, 1-20.

Tierney, P., \& Farmer, S. M. (2002). Creative self-efficacy: Its potential antecedents and relationship to creative performance. Academy of Management Journal, 45, 1137-1146.

Tubre, T. C., \& Collins, J. M. (2000). Jackson and Schuler (1985) revisited: A meta-analysis of the relationship between role ambiguity, role conflict and job performance. Journal of Management, 26, 155-169. 
RAUSP

55,4

Walia, K., \& Narang, S. (2015). Job stress and job involvement: A study of IT professionals from North India. Prabandhan: Indian Journal of Management, 8, 39-50.

Yasir, M., \& Majid, A. (2019). Boundary integration and innovative work behavior among nursing staff. European Journal of Innovation Management, 22, 2-22.

Zhang, X., \& Bartol, K. M. (2010). Linking empowering leadership and employee creativity: The influence of psychological empowerment, intrinsic motivation, and creative process engagement. Academy of Management Journal, 53, 107-128.

Zhao, Y., \& Cavusgil, S. T. (2006). The effect of supplier's market orientation on manufacturer's trust. Industrial Marketing Management, 35, 405-414.

Corresponding author

Subhash C. Kundu can be contacted at: sckundu@yahoo.com

Associate Editor: Sachin Kumar Mangla

For instructions on how to order reprints of this article, please visit our website: 